\title{
¿INTEGRACIÓN SOCIAL Y SUBORDINACIÓN POLÍTICA DE LOS AYMARA? UN ESTUDIO DE LA CERTIFICACIÓN ESTATAL INDÍGENA EN EL NORTE CHILENO
}

\author{
Vivian Gavilán Vega y Felipe Lagos Candia ${ }^{1}$
} \begin{abstract}
Los procesos de integración/inclusión del pueblo aymara a la comunidad política y nacional constituye el interés central de una investigación en curso, cuyo punto de partida fue conocer la respuesta de la colectividad aymara de la Región de Arica-Parinacota a las iniciativas estatales de discriminación positiva. Revisamos aquí antecedentes relacionados con el proceso de acreditación de la condición indígena, provenientes de la Corporación Nacional para el Desarrollo Indígena (CONADI). El análisis de estos datos nos planteó varias preguntas en torno a las experiencias de ser ciudadano e indígena hoy, y que son abordadas en este artículo. Una estrategia metodológica complementaria fue entrevistar a personas que solicitaron la certificación, con la finalidad de conocer sus argumentos y explorar en los significados que elaboran los actores. Los resultados muestran que el Estado persiste en políticas asistencialistas, en tanto que la colectividad aymara continúa buscando nuevas formas de cumplir sus aspiraciones de ser parte de la sociedad mayor.
\end{abstract}

Palabras claves: etnicidad - ciudadanía - pueblos originarios - aymara

The main purpose of this research is the process of integration/ inclusion of the Aymara people into political and national community.

The starting point was to know the answer or response of Aymara community (Arica-Parinacota) to the affirmation politic raised

from the state. Here we analyzed data related to the process called indigenous condition accreditation, impulse by the national corporation for the indigenous development (CONADI). This raised several questions about the experience of being and indigenous citizen today addressed in this article. A complementary methodology was to interview people who applied for the certification, with the intention

to now their argument and study the meanings elaborated by the

actors. The data analyses show that the state insist in paternalistic politics, meanwhile the Aymara community keep looking for new ways to by a part of the hegemonic society.

Key words: ethnicity - citizenship - indigenous people - aymara. Recibido: abril 2013. Aceptado: agosto 2014.

\section{* Introducción}

El título de este artículo hace referencia a la discusión planteada por M. Hopenhayn en torno a la situación de las democracias actuales y la ampliación de la ciudadanía a los derechos culturales en Latinoamérica. En este trabajo nos interesa reflexionar sobre los procesos de integración/inclusión social y cultural de los pueblos originarios en Chile. Con base en datos levantados en el desarrollo de una investigación en curso sobre la relación del Estado nación chileno con el pueblo aymara, presentamos avances relacionados con la certificación indígena en el norte del país, mecanismo estatal para ejecutar políticas subsidiarias tendientes a disminuir la pobreza y a aplicar políticas de discriminación positiva.

La masiva participación de la población aymara del norte chileno en esta "convocatoria" y la aparente débil reacción de las organizaciones que reivindican derechos culturales ante las actuales políticas integracionistas, podrían sostener la idea que la colectividad aymara no logra poner en discusión las actuales estrategias de dominación. Los datos que presentamos informan que la amplia participación de las familias aymara por obtener este tipo de reconocimiento se inscribe en un contexto de aspiraciones por lograr mayor inclusión social. Situación que ha estado presente a lo largo del siglo XX, pero con una fuerte subordinación cultural. No obstante, los argumentos entregados por los/las entrevistados/as indican que si bien son activos beneficiarios del Estado, al mismo tiempo

\footnotetext{
1 Departamento de Antropología, Universidad de Tarapacá. 18 de Septiembre 2222 - Casilla 6D, Arica, CHILE. Email: vtgavilanv@uta.cl y felipelagoscandia@hotmail.com
} 
reflexionan sobre la diferencia cultural y se expande la concienciación étnica en el contexto del Estado-nación moderno.

El Estado y sus políticas de discriminación positiva se despliegan desde el enfoque de la multiculturalidad, más como realidad a gestionar (Zapata-Barrero 2004: 249) que como proyecto inclusivo de las diferencias culturales; vale decir, como proceso social en el que las diferencias culturales no son vistas como amenaza a la nación chilena. En este sentido, la certificación de la condición indígena sería un dispositivo estatal para continuar con la integración de los pueblos originarios a la sociedad nacional. Esto a pesar del reconocimiento público y de las declaraciones y/o convicción por conducir procesos crecientes de inclusividad. Esta procede vía un trámite individual y/o colectivo según exigencias jurídicas determinadas por la Ley Indígena 19.253. De aquí que nos interesamos por estudiar las bases de datos disponibles en la Corporación Nacional para el Desarrollo Indígena (CONADI), institución encargada de poner en marcha los programas estatales para la población que dice descender de las comunidades originarias. En la Región de Arica y Parinacota se registran las acreditaciones realizadas a partir de 1995, dos años después de que esta ley entrara en vigencia. Nos pareció una importante fuente de información para obtener evidencia empírica sobre la situación de la población aymara regional. Complementariamente, aplicamos entrevistas a personas que solicitaron la certificación con la finalidad de conocer sus argumentos y sus representaciones sobre las implicancias de este proceso.

A partir del año 2005 en la actual Región de Arica y Parinacota, territorio administrativo en el que se localiza la mayoría de la población aymara del país, se produce un aumento sustantivo de personas que buscan la certificación estatal de su pertenencia a alguno de los nueve pueblos originarios reconocidos por el Estado y nación chilenos. Frente a estos antecedentes, las preguntas que formulamos fueron: ¿a qué se debe este creciente interés por buscar el reconocimiento estatal? La asociación entre acreditación indígena y acceso a beneficios sociales es evidente, pero ien qué consiste este proceso, cómo procede, quiénes son los que concurren?, ¿qué implica reconocerse étnicamente hoy para las personas? Y finalmente, la pregunta central que nos convoca iqué significa ser ciudadano e indígena para los aymara contemporáneos?

Aparentemente las voces disidentes que cuestionan la hegemonía cultural son débiles y no se observa un movimiento social dirigido a cambiar las actuales relaciones de poder. Si bien parece continuar la política estatal de integración a través de la síntesis de las diferencias en la diversidad social, a nivel de los sujetos concretos se estaría produciendo un proceso de mayor concienciación étnica en el contexto del Estado y nación modernos. Aunque la interpelación al Estado es dispersa, se oyen voces disidentes que cuestionan la hegemonía cultural.

El análisis de la base de datos consideró todas las variables identificadas por la oficina de CONADI para la Región de Arica-Parinacota. Dos de ellas -la edad de los inscritos y la fecha en la que se producen las acreditaciones- indican un claro interés por obtener becas estudiantiles. Por ende, revisamos también los antecedentes disponibles en la Junta Nacional de Auxilio Escolar y Becas (JUNAEB), institución encargada de las ayudas estatales en educación.

Las entrevistas se aplicaron a once personas de diferentes edades, de distintos lugares de procedencia, con niveles de escolaridad diferenciados y con residencia urbana y rural. Tratamos de conocer su visión de la certificación, a través de entrevistas abiertas. A partir de estos resultados elaboramos una nueva pauta dirigida a profundizar en la valoración que asignan a la certificación.

El presente artículo parte con la contextualización del problema que plantea el proceso de integración/inclusión social y cultural de los pueblos originarios en las sociedades nacionales en América Latina, y en Chile en particular. Continúa con una reseña del cuerpo jurídico en el que opera el reconocimiento indígena, para pasar a la presentación e interpretación de los datos. Termina con reflexiones finales.

\section{* Alteridad e inclusión social de la COLECTIVIDAD AYMARA EN EL NORTE CHILENO}

Hoy sabemos que los pueblos originarios en América Latina, insertos en las dinámicas modernizadoras de 
los Estados naciones, han experimentado procesos étnicos discriminatorios y excluyentes. Las políticas integracionistas con fines de asimilación cultural han sido cuestionadas por movimientos sociales en las que las identidades étnicas forman parte central de la lucha política. Estos procesos contra-hegemónicos han seguido caminos dispares entre países, así como al interior de cada país. Las colectividades indígenas han enfrentado muchas dificultades para desarrollar una lucha permanente en contra de las políticas neoliberales en la economía y en contra de las políticas de dominación de las democracias formales vigentes en el continente. Como señalan Hopenhayn y colaboradores (2006: 49), la ciudadanización en América Latina no ha sido homogénea en su desarrollo, ni responde a los mismos principios, demandas y objetivos cuando se analiza por país. Asimismo, se presentan diferencias al interior de los países. En Chile, por ejemplo, los procesos reivindicativos del pueblo mapuche no son iguales a los del pueblo aymara.

Giménez (2000) ha sugerido que las demandas de las colectividades de origen indígena en América Latina por mayor inclusión en la sociedad deben entenderse en un contexto histórico de exclusión. Propone que, para comprender su situación social y política en los Estados naciones modernos, se precisa distinguir distintos planos de ciudadanía. Una cosa es formar parte de la comunidad nacional y otra ser miembros de una comunidad política y el carácter de la pertenencia a esta última considera, además, diferentes tipos de derechos. En este sentido, la etnicidad y sus vínculos con la ciudadanía dependen de las particularidades históricas de cada país. Por su parte Bengoa (2000 y 2009) ha argumentado que los procesos de emergencia indígena plantean el desafío de una nueva ciudadanía, pues ser ciudadano de la nación y miembro del pueblo indígena no implica contradicción. Sugiere que hemos asistido a un proceso de descolonización, en el que los indígenas buscan apropiarse como "ciudadanos étnicos" de los instrumentos e instituciones del Estado y no retraerse a sus comunidades originarias. Sin embargo, sostiene que si bien los avances hacia el reconocimiento de los pueblos originarios por parte de la sociedad nacional y del Estado son significativos, no podemos perder de vista que la hegemonía cultural persiste en la práctica social y en la práctica jurídica.
Para situar la problemática en el caso chileno es posible identificar dos posturas: aquella que considera el rol activo que han cumplido los pueblos originarios en las políticas estatales, es decir la participación de los mismos en pactos sociales importantes (Vergara et al. 2006), y la lectura de la relación del Estado con los pueblos originarios en un contexto de dominación de arriba hacia abajo (Boccara y Bolados 2010). La primera visión reconoce la incapacidad política del Estado y de los partidos políticos para enfrentar los problemas de los pueblos indígenas. Se arguye que post Ley Indígena se habría producido un alejamiento de los colectivos indígenas respecto del gobierno y de la CONADI, una pérdida de confianza en las organizaciones aliadas y se habría reforzado el movimiento mapuche más confrontacional (Vergara et al. 2006). La segunda mirada plantea que se precisa abordar la cuestión de la naturaleza del multiculturalismo neoliberal en Chile y el establecimiento de un tipo de poder que denomina "etnogobierno". El autor, centrado en las prácticas concretas del accionar del Estado, postula que el tratamiento que realizan sus agentes se orienta a considerar a los indígenas más como clientes que como ciudadanos (Boccara y Bolados 2010).

Ambas posturas recogen diferentes dimensiones del proceso de integración/inclusión en la comunidad nacional y política. Sin embargo, la perspectiva que pone énfasis en la administración estatal de las etnicidades tiende a perder de vista los procesos microsociales de concienciación étnica y ciudadana. Este trabajo muestra que la cuestión de los efectos de las prácticas estatales en la colectividad étnica requiere de mayor investigación. Sabemos que en muchos casos las políticas dirigidas a la gobernabilidad acarrean como resultado posiciones anti-hegemónicas. En México, por ejemplo, varias políticas públicas se tradujeron en procesos de etnogénesis (Bello 2004). Siguiendo a Hopenhayn (2001), Bello señala que la percepción de las políticas sociales en América Latina ha sido heterogénea y que los procesos de hegemonía pueden ser revertidos o reapropiados por sus destinatarios en beneficio propio. En este sentido, las políticas y proyectos del Estado son apropiados y resignificados por los actores, quienes los convierten en espacios propicios para la reproducción de las identidades.

La particularidad del caso de los pueblos originarios del norte chileno se halla en el hecho de residir en un 
territorio recientemente anexado ${ }^{2}$ y aún en proceso de legitimidad nacional. En este sentido, si bien por parte de la colectividad aymara la adscripción nacional está afincada, la asociación que realiza la comunidad chilena entre tradiciones indígenas y nacionalidad peruana y/o boliviana, ha implicado un permanente cuestionamiento a su pertenencia. Esto significa que la posibilidad de considerar a las familias aymara como connacionales exige subordinar las prácticas sociales y culturales que comparten como descendientes de los pueblos originarios a las prácticas sociales de la comunidad nacional; esto es, impone como condición para ser ciudadanos modernos, dejar de ser indígena. Situación que no ocurre con el pueblo mapuche dada su condición de fundacional en la construcción de la "comunidad imaginada". De este modo, la persistencia del estigma colonial del indio constituye la base de la interrogación sobre la lealtad a la nación, pero si a ello se añade el hecho de compartir la misma tradición indígena con colectividades peruanas y bolivianas, la membresía nacional no es fácil.

La pertenencia de los aymara a la comunidad política ha sido más difícil. La participación efectiva de los "ciudadanos indios" ha sido heterogénea. A modo de hipótesis, es posible afirmar que aquel grupo que tendió a una creciente asimilación, como efecto del modelo de modernización instaurado en el período de explotación del nitrato de sodio -desarrollado durante la segunda mitad del siglo XIX y a lo largo del XX- avanzó a una ciudadanización creciente, especialmente por la importancia que tuvo el movimiento obrero a nivel regional, nacional e internacional. Pero, a lo largo del siglo XX el conjunto de la población originaria ha bregado por alcanzar mayor integración. Es en la década de los ochenta cuando emergen organizaciones que reivindican derechos ciudadanos a la diferencia cultural. Esto marca un hito en la región y a nivel nacional pues es la primera vez que se plantea -desde abajo- una nueva forma de participar en la comunidad política. Este proceso se sella con la Ley Indígena aprobada en 1993. Si bien la relación Estado-pueblo aymara establecida en los últimos 20 años apuesta por el reconocimiento de la diferencia cultural, el ejercicio de la ciudadanía plantea varios problemas.

\footnotetext{
2 En 1879, después de la Guerra del Pacífico, se anexó la provincia de Tarapacá correspondiente al extremo sur peruano durante el siglo XIX.
}

Gundermann (2003: 54), sostiene que el tránsito de indio a ciudadano implicó para las comunidades aymara transformaciones que las condujeron a su integración a la comunidad nacional y política. Postula que, más que una conciencia indígena de la ciudadanía intelectualizada y formalizada de derechos y deberes en relación con una comunidad política, se codifica y verbaliza en un argumento y demanda por una mayor integración social, pues el fundamento de la validez y legitimidad de esos requerimientos son los deberes del Estado para con la población. Postula que, en los últimos sesenta años, la etnicidad y la identidad social de indio desplegaron una decidida actitud de integración social y asimilación cultural. Reconoce dos aspectos en este proceso. Por una parte, se presenta una negación sistemática de los contenidos culturales que operaban como marcadores de identidad sociocultural, sostenida en una visión estereotipada de su valor y su inutilidad para enfrentar los procesos modernizadores planificados por el Estado. Por la otra, se hace presente una visión igualmente incompleta y limitada, pero con una valoración cuyos signos son inversos, es decir, adquieren ciertos marcadores étnicos e instrumentos culturales estratégicos que provienen de la población mayoritaria. La ideología que legitima tales contenidos es la de la civilización y el progreso. Desde el Estado y desde las propias comunidades, en la medida que lo acepten, la asimilación se enviste como proyecto civilizatorio. De este modo, sugiere que se podría postular una comunidad de intereses entre aymaras y Estado en función de la transformación social y cultural indígena, puesto que las tendencias progresistas de las políticas estatales han sido adoptadas por las comunidades y encuentran en la administración pública regional una buena contraparte para implementar acciones. Los intereses de los indígenas por integrarse al Estado nación chileno habrían implicado la pérdida de etnicidad, de cultura, de alteridad y su recambio por formas culturales populares en la región. Gundermann (2003) toma como base empírica para esta afirmación lo que él llama la obsesión por su inserción en el sistema escolar, pues fue vista como medio para acceder a los recursos de la modernidad. Este comportamiento se entiende en un contexto en el que las relaciones interétnicas habrían estado determinadas por la sociedad nacional que estigmatiza a la sociedad y a la cultura de origen indígena. En este sentido, la colectividad aymara se fue configurando como una minoría subordinada con identidades definidas desde el otro, afirmando el estigma 
de indio construida por los europeos. Para este autor, la aceptación de este orden por parte de los aymara implicó e implica relaciones de dominio y subordinación, pero no necesariamente de conflicto interétnico ya que existiría un cuerpo de propósitos común en torno a la asimilación y la disolución del indígena en la sociedad mayor. La inversión pública realizada en el norte chileno en los últimos 30 años habría conducido a configurar a la población indígena regional como cliente y dependiente de las prestaciones estatales. Así, entre las consecuencias del accionar del Estado se hallaría una dilapidación de recursos en función de mantener clientelas y desarrollar relaciones clientelares, problemas de coordinación y diagnóstico en la colocación de recursos y prestaciones, corrupción de grupos beneficiarios, conflictividad por el control de recursos, entre otros.

La integración política, es decir la producción de ciudadanos modernos, ha presentado más obstáculos que en el conjunto de la población regional. Si bien parecen haber apostado por la integración a la sociedad nacional, el cuestionamiento de la exclusión social y cultural que realiza el movimiento de los años ochenta genera una nueva forma de ser ciudadanos: exigen formar parte de la comunidad política siendo diferentes culturalmente. Sin embargo, con posterioridad a la Ley Indígena en 1993 se producen fisuras importantes en la relación con el Estado, se fragmentan las organizaciones y se debilita su fuerza.

El cuestionamiento del principio Estado=nación ha sido débil si lo comparamos con el pueblo mapuche y con otros movimientos latinoamericanos. Uno de los problemas más serios que enfrentan los líderes es la ausencia de una organización amplia y representativa. Existe un gran distanciamiento entre dirigentes y bases, los conflictos que ha generado la inserción de los líderes en puestos públicos los lleva a una dispersión que ha estancado un proceso de articulación. Reconocen un retroceso de la movilización generada en la década de los noventa, situación que explican por factores externos, como por ejemplo, la intromisión de los partidos políticos, más no identifican las dificultades de representatividad o del escaso apoyo de las localidades de base. Aunque la desconfianza de la institucionalidad política es generalizada en la región, los dirigentes de la causa indígena enfrentan mayores dificultades por la inexistencia de una colecti- vidad cohesionada en torno a reivindicaciones comunes. Es posible que esto ocurra por la fuerte identidad localista que se ha observado en la región (González y Gavilán 1990). No obstante, los efectos de tres décadas de reconocimiento étnico del pueblo aymara a nivel regional y nacional y del aprendizaje adquirido por parte de las familias aymara en un contexto político diferente a los históricamente experimentados, tiene como consecuencia la construcción de un tipo de etnicidad diferente a la existente durante el siglo XX. En este sentido, es importante avanzar en el conocimiento de qué es ser ciudadano e indígena para los aymara del norte chileno. Los datos que aquí presentamos señalan que aun cuando las políticas de discriminación positiva se instalan en un contexto de multiculturalismo que busca el etnogobierno, la participación de los aymara en estos procesos estaría conduciendo a un proceso de expansión de la conciencia étnica en un contexto político democrático, es decir se va haciendo presente una colectividad étnica consciente de sí misma en el contexto del Estado nación moderno.

\section{* La certificación indígena como mecanismo DE INTEGRACIÓN AL ESTADO-NACIÓN}

La gestión y obtención de la certificación de la calidad indígena es un acto voluntario de identificación individual y colectiva. Las acreditaciones son impartidas por la Corporación Nacional para el Desarrollo Indígena (CONADI), amparada en la Ley Indígena 19.253 y en un reglamento que regula la ejecución y validez de las mismas. ${ }^{3}$ Este reglamento se basa en el artículo segundo de dicho cuerpo jurídico y plantea como requisito la documentación (legalmente autentificada). Considera tres criterios de identificación para ser considerado "indígena": pertenencia ancestral, pertenencia a un linaje y autoidentificación cultural. El primero se refiere a "... hijos de padre o madre indígena, cualquiera sea la naturaleza de su filiación, inclusive adoptiva, la que se entenderá por hijos de padre o madre indígena a quienes desciendan de habitantes originarios de las tierras identificadas en el Artículo 12, número

3 El 12 de Abril de 1994 se publicó en el Diario Oficial el Decreto Supremo N 392 : Aprueba Reglamento que Regula la Acreditación de la Calidad de Indígena para la Constitución de las Comunidades Indígenas y para la Protección del Patrimonio Histórico de las Culturas Indígenas. 
I y $2 . . . .{ }^{4}$ Comprende, así, a las personas que descienden de ancestros que provienen de las tierras correspondientes al Artículo 12, número 1 y 2. El segundo apela a “... los descendientes de las etnias indígenas que habitan el territorio nacional, siempre que posean a lo menos un apellido indígena; un apellido no indígena será considerado indígena, para los efectos de esta ley, si se acredita su procedencia indígena por tres generaciones...." Este criterio se certifica con el desarrollo de un árbol genealógico que se anexa al formulario de solicitud de la certificación, ${ }^{6}$ como también, al certificado de inscripción del Registro Civil de cada uno de los ancestros invocados. El tercero postula se consideran indígenas quienes "... mantengan rasgos culturales de alguna etnia indígena, entendiéndose por tales la práctica de las formas de vida, costumbres o religión de estas etnias de un modo habitual o cuyo cónyuge sea indígena. En estos casos, será necesario, además que se auto identifiquen como indígenas..."? Este criterio debe certificarse con la presentación de un documento notarial de parte del sujeto y de la comunidad, el cual tendrá un carácter permanente e irrevocable. Frecuentemente bajo esta categoría se autoidentifican las personas que contraen un vínculo conyugal o las personas migrantes de otros países (Perú y Bolivia frecuentemente).

Si bien el reglamento de aplicación de la certificación de la calidad indígena se rige por las normas que regulan el párrafo $\mathrm{N}^{\circ} 2$ de la Ley 19.253 , cada oficina regional tiene la facultad de agregar mecanismos que considere pertinentes. En el caso de la Región de Arica y Parinacota, que constituye una zona de alta concentración indígena, junto al Decreto Supremo $\mathrm{N}^{\circ} 392$ se aplica un instrumento anexo para definir algún tipo de vínculo genealógico ${ }^{8}$

4 Letra a) Artículo $2^{\circ}$, Párrafo $2^{\circ}$ TITULO I, Ley $N^{\circ} 19.253$, Ley Indígena.

5 Letra b) Artículo $2^{\circ}$, Párrafo $2^{\circ}$ TITULO I, Ley $N^{\circ} 19.253$, Ley Indígena.

6 La certificación de la calidad de indígena gestionada por $\mathrm{CO}$ NADI proviene de un cuerpo jurídico común, pero su proceso operacional difiere en las distintas oficinas, produciendo, como consecuencia, ligeras variaciones en la incorporación de un árbol genealógico a la solicitud de la certificación de la calidad de indígena en las oficinas de la CONADI de la ciudad.

7 Letra c) Artículo 2 ${ }^{\circ}$, Párrafo $2^{\circ}$ TITULO I, Ley N 19.253 Ley Indígena.

8 La anexión del requerimiento "vínculo genealógico" se ejecuta a nivel local sobre la base de un mapa genealógico adjuntado a la ficha de solicitud de dicho certificado. con un linaje indígena aymara. Este instrumento, denominado "Catastro de apellidos usados por indígenas aymaras en la Región de Arica y Parinacota", fue desarrollado el año 2008 por un dirigente aymara y funcionario público en colaboración con una consultora, con lo cual se reconoce y ratifica la calidad de indígena a través de los apellidos heredados ancestralmente.

Las acreditaciones impartidas por CONADI regional entre los años 1995 y 2009 alcanzaron a 27.346 personas, volumen que se fue incrementando de manera sustantiva durante este período. Sin embargo, a partir del año 2005 se produjo un aumento anual sorprendente. Esta cifra superó con creces el número de adscritos al pueblo aymara en el censo poblacional (2002) y la registrada en la última encuesta de hogares (CASEN 2009) para la región.

La asociación entre certificación y beneficios sociales es la primera respuesta que podemos establecer si consideramos el carácter de las políticas sociales en un modelo económico neoliberal como el que impera en el país, y si recordamos los procesos de exclusión social históricos que han afectado a las comunidades indígenas y a los sectores populares, en general. La focalización de las políticas sociales en los grupos más vulnerables, dentro de los cuales se inscribe a la población indígena, puede ser la estrategia actual del Estado para la integración a la sociedad nacional. Pero, ¿en qué consiste esta asociación?, ¿cuáles han sido las respuestas de la colectividad aymara regional a estas políticas?

\section{* La Certificación de la CONDiCión indígena EN LA COMUNA DE ARICA y El CONTEXTO SOCIOPOLÍTICO NACIONAL}

La evolución histórica de las inscripciones en CONADI Arica-Parinacota9 (Tabla 1) indica que existe un incremento paulatino de inscripciones a partir del año 1995. En los primeros años de aplicación de la Ley Indígena (1995-1999) se observó un ascenso tímido pero sostenido, llegando a las 1136 inscripciones, equivalentes al $4,1 \%$, del total de los registros actuales. En el período

\footnotetext{
9 Hasta el año 2009 la actual Región de Arica y Parinacota correspondía a una provincia de la región de Tarapacá.
} 


\begin{tabular}{|c|c|c|c|c|c|}
\hline Año de acreditación & $\begin{array}{c}\mathbf{N}^{\circ} \text { de Inscritos } \\
(\mathrm{fi})\end{array}$ & Porcentaje (hi) & $\begin{array}{c}\text { Inscritos acumulados } \\
(\mathrm{Hk})\end{array}$ & $\begin{array}{c}\text { Porcentajes acumulados } \\
(\mathrm{Fk})\end{array}$ & $\begin{array}{c}\text { Rango entre porcentajes } \\
\text { anuales }(\mathbf{R})\end{array}$ \\
\hline 1995 & 93 & 0.3 & 93 & 0.3 & 0.3 \\
\hline 1996 & 12 & o & 105 & 0.3 & 0.4 \\
\hline 1997 & 118 & 0.4 & 223 & 0.7 & 0.6 \\
\hline 1998 & 288 & 1.1 & 511 & 1.8 & 1.2 \\
\hline 1999 & 625 & 2.3 & 1136 & 4.1 & 1.7 \\
\hline 2000 & 1088 & 4 & 2224 & 8.1 & 2.2 \\
\hline 2001 & 1676 & 6.1 & 3900 & 14.2 & 0.8 \\
\hline 2002 & 1446 & 5.3 & 5346 & 19.5 & 0.4 \\
\hline 2003 & 1564 & 5.7 & 6910 & 25.2 & 0.5 \\
\hline 2004 & 1703 & 6.2 & 8613 & 31.4 & 3.6 \\
\hline 2005 & 2693 & 9.8 & 11306 & 41.2 & 3 \\
\hline 2006 & 3504 & 12.8 & 14810 & 54.0 & 2.1 \\
\hline 2007 & 2921 & 10.7 & 17731 & 64.7 & 6 \\
\hline 2008 & 4565 & 16.7 & 22296 & 81.4 & 1.8 \\
\hline 2009 & 5050 & 18.5 & 27346 & 99.9 & 81.5 \\
\hline Total & 27346 & 100 & $\circ$ & 100 & o \\
\hline
\end{tabular}

Tabla 1. Acreditación de personas indígenas aymara, comuna de Arica 1995-2009. Fuente: elaboración propia en base a registros CONADI Arica-Parinacota (Ley de Transparencia 20.285).

comprendido entre 2000 y 2001 se produjo un aumento de 588 inscripciones por año, alza que se mantuvo con una escasa diferencia hasta el año 2004. A partir del año 2005 el número de inscritos por año se duplica, llegando su máximo valor en 2009, año en el que se agregaron 5050 personas.

La ilustración de estos datos evidencia dos momentos de auge. El primero, entre 1998 y 2000 marca una diferencia positiva hacia un incremento tenue pero sostenido, $y$ el segundo, entre los años 2004 y 2009, en el que se registran las diferencias más extremas, alcanzando incluso el $6 \%$ de diferencia entre los años 2007 y 2008.

Si bien el ascenso es sostenido, en los años 2002 y 2003 el número de certificaciones bajó. Lo mismo sucede el año 2007, si comparamos los años 2006, 2008 y 2009; siendo este último el período que alcanza su mayor alza con 5050 personas inscritas desde su implementación en el año 1995. Si revisamos el contexto sociopolítico en el que se fue dando el creciente interés por buscar la acreditación, vemos que este responde a las políticas diseñadas por los gobiernos de la Concertación de Partidos por la Democracia que gobernó durante 20 años. Aylwin (2004) señala que a seis años de la promulgación de la Ley Indígena 19.253, los pueblos originarios organizados vivieron una gran desmotivación por la implementación de una ley despojada de los principios fundamentales acordados en el pacto de Nueva Imperial en 1989, ya que gran parte de las reivindicaciones planteadas en este no se retomaron en la formulación de la misma. Argumenta que las políticas diseñadas durante el gobierno de Eduardo Frei (1994-2000) fueron dirigidas a desplazar los derechos indígenas (mediante la criminalización del movimiento mapuche, recurriendo a la Ley de Seguridad del Estado 12.927), y a respaldar la inversión privada en sus territorios sin consultarlos, ${ }^{10}$ lo cual habría incidido en un alejamiento entre los pueblos originarios y el Estado. Pero este distanciamiento no fue homogéneo. Se produjo una fragmentación interna entre y al interior de los pueblos originarios. Una parte de la colectividad

${ }^{10}$ La Ley Indígena y las otras normas que regulan los recursos naturales que se encuentran en territorio indígena (el Código de Aguas de 1981, el Código de Minería de 1983 y la Ley de Bases del Medio Ambiente de 1994, entre otras) no protegen a las comunidades de los grandes proyectos de inversión extractiva o productiva. 


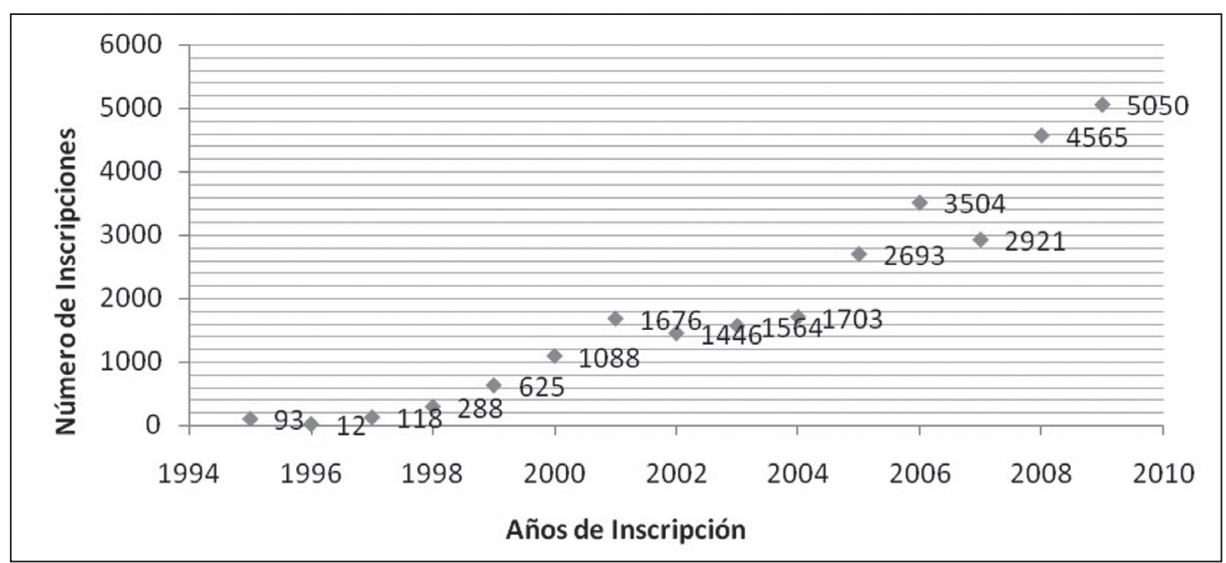

Figura 1. Distribución anual de acreditaciones de la calidad de indígena entre los años 1995-2009, comuna Arica, región de Arica y Parinacota. Fuente: Elaboración Propia Registros CONADI Arica-Parinacota (Ley de Transparencia 20.285).

mapuche se radicalizó, en tanto que la aymara tendió a aceptar el estado de cosas. El año 2001 el Estado creó el Programa Orígenes, con fondos propios y en cooperación con el Banco Interamericano de Desarrollo (BID), para "mejorar la calidad de vida" de las personas indígenas. Este programa desplegó su accionar en pos del desarrollo integral de comunidades, tanto a nivel rural como urbano. Asimismo, en este año la creación de la Comisión Verdad Histórica y Nuevo Trato buscó generar un diagnóstico de las demandas indígenas e impulsar una nueva política hacia los pueblos originarios. En el año 2003 se dio a conocer el informe final emitido por esta Comisión. En él se reconocieron errores en el accionar del Estado y se propuso una serie de reformas jurídicas, políticas y económicas orientadas a reparar los daños causados. Esto permitió el establecimiento de un "nuevo trato", pacto basado oficialmente en el reconocimiento de los derechos políticos, territoriales y culturales de "carácter colectivo de los pueblos indígenas". Como una forma de responder a las observaciones realizadas por el relator de las Naciones Unidas, Ricardo Lagos anunció en Abril del año 2004 la implementación de la política del "Nuevo Trato", comprometiéndose a introducir una serie de medidas en favor de los pueblos originarios. Entre estas se encontraban el reconocimiento constitucional de estos pueblos; la ratificación del Convenio 169 de la OIT; el fortalecimiento sociocultural indígena; el fomento al desarrollo productivo; impulsar las transformaciones legislativas para establecer un Consejo de Pueblos con representación indígena; el reconocimiento de los derechos indígenas sobre el borde costero y la restitución de tierras y aguas (Gobierno de Chile, Nuevo Trato con los Pueblos Indígenas. Mayo, 2004). ${ }^{11}$

Con la presidenta Michelle Bachelet se mantienen estos compromisos, pero con ella se fortalecen las políticas redistributivas asentadas en la protección social. Tanto el programa de gobierno de Bachelet, como el acuerdo de Nueva Imperial del año 2006 y los ejes de la política indígena del año 2007 , configuran una nueva arremetida estatal que convergerá en la emergencia de un "nuevo" pacto social por la multiculturalidad llamado "Re-conocer", ${ }^{12}$ lanzado en el mes de Abril del año 2008.

${ }^{11}$ Estas medidas fueron incorporadas con profundas contradicciones. Las críticas sobre el doble estándar de la Ley Indígena y los desprestigios en materia legal con respecto a la institucionalidad por el caso de la central hidroeléctrica Ralco en el Alto Bío-Bío crearon fuertes tensiones entre el estado y los pueblos originarios. Además, dicho gobierno no acató las observaciones del Relator de las Naciones Unidas con respecto a lo que llamó el fenómeno de la "criminalización" de la legítima protesta social mapuche, con la aplicación de la Ley Antiterrorista (Ley 18.314 de 1984, modificada el año 1991 y 2002) a dirigentes y comuneros mapuches (Aylwin 2004).

12 El nuevo plan de acción se estructuró en torno a tres áreas: a) sistema político, derechos e institucionalidad; b) desarrollo integral de los pueblos, y c) multiculturalismo y diversidad. No ajeno a las críticas, cada área y eje temático está detallado en un conjunto de actividades específicas que se traducen en: el incremento del programa de becas, la incorporación de subsidios habitacionales, residencias para estudiantes indígenas, restitución progresiva 


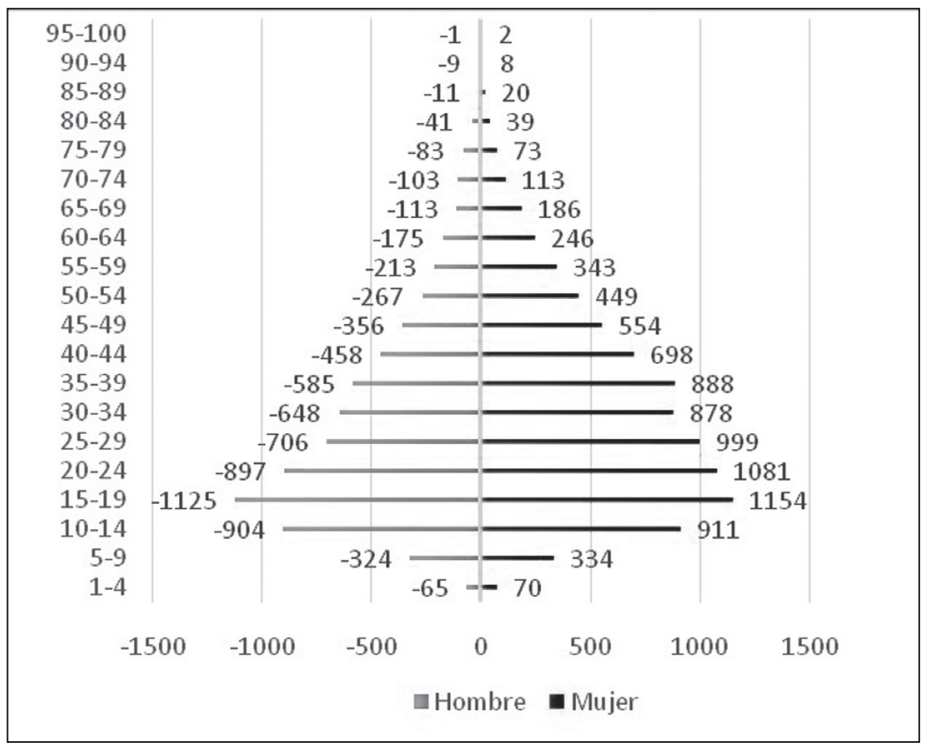

Figura 2. Edades quinquenales de la población inscrita en los registros de CONADI, entre los años 1995-2008. Fuente: Elaboración Propia Registros CONADI Arica-Parinacota.

Las políticas sociales del gobierno de Bachelet implicaron un progresivo aumento de becas, subsidios habitacionales y seguridad social, acciones que fueron dirigidas por CONADI. Siguiendo el formato jurídico, ésta opera a través de la identificación de la población como perteneciente a alguno de los nueve pueblos originarios que reconoce el Estado en la actualidad. De esta manera, se puede afirmar que el aumento del número de acreditaciones expone la gran aceptación que han tenido las políticas de discriminación positiva por parte de la colectividad aymara.

\section{* Caracterización de la población CERTIFICADA}

Para caracterizar a la población que ha sido certificada ocupamos una segunda base de datos digitalizada disponible en CONADI, cuya información corresponde a los años comprendidos entre 1995 y 2008 , e incluye las variables pertenencia a algún pueblo originario, lugar de nacimiento, sexo, edad, categoría legal de acreditación y

de tierras, mejoramiento del programa de salud indígena, y la creación de un espacio costero marino de los pueblos originarios, entre otras reformas. fecha de recepción de la solicitud de acreditación. Esta base de datos cuenta con un universo de 22296 personas inscritas en la Comuna de Arica que declaran pertenecer a todos los pueblos que reconoce la Ley Indígena. El 92\% de los acreditados declara pertenecer a la etnia aymara y solo un $8 \%$ se identifica como perteneciente a otro pueblo originario.

La mayoría de quienes declaran pertenecer al pueblo aymara (73\%) nació en la comuna de Arica (urbana). La segunda mayoría corresponde a quienes nacieron en la localidad de Putre (rural, 4\%). Le siguen en importancia las personas que nacieron en Belén (zona rural, 3,2\%). ${ }^{13}$ Así, vemos que un poco más de dos tercios de la población pertenecen a la generación nacida en la ciudad. Respecto de la distribución por edades, las personas que solicitan esta certificación corresponden mayoritariamente a jóvenes con una media de 23 años, encontrándose casos extremos de personas con un máximo de 110 años y un mínimo de 2 años. Al ser la certificación un acto voluntario e individual de autoadscripción es extraño el registro de los menores. Si consideramos a los

${ }^{13}$ Lo que resta de esta población procede de la zona altiplánica y valles de la zona norte, de algunas ciudades nortinas, $y$-en menor medida- de la zona centro y sur del país. 
inscritos entre 2 y 15 años, vemos que representan el 16\% de los inscritos.

La desviación estándar es de 20 años, provocándose una gran variabilidad de la secuencia con respecto a las edades en cuestión. Mientras los menores son inscritos por los padres, los más ancianos solicitan la certificación como una manera de facilitar la membresía étnica de su descendencia. La distribución por sexo muestra un predominio de mujeres, con el 55\% de las inscripciones. Dentro de esta proporción, las mujeres sobrepasan ligeramente en edad a los hombres porque tienen una media de 25 años, frente a la de los hombres que alcanza los 22 años.

Según las categorías que establece la Ley 19.253 para acreditar a los ciudadanos como indígenas, vemos que en su mayoría (57\%) se acogen al acápite que señala reconocer como tales a "los descendientes de las etnias indígenas que habitan en el territorio nacional, siempre que posean al menos un apellido indigena, dentro de las tres últimas generaciones...". Una proporción menor (39\%) lo hace por ser hijo de padre o madre indígena. Muy por debajo de los porcentajes anteriores $(3,7 \%)$, adhiere al artículo que reconoce como indígena a quienes "mantengan rasgos culturales de alguna etnia indígena, entendiéndose por tales la práctica de las formas de vida, costumbres o religión de estas etnias de un modo habitual o cuyo cónyuge sea indígena. Sólo un grupo pequeño se incluye por tener un vínculo conyugal $(2,8 \%)$ o por ser migrantes bolivianos y peruanos que se adscriben a algún pueblo indígena (véase Figura 3).

Los requerimientos jurídicos para establecer la ciudadanía étnica no necesariamente se ajustan a la condición de descendientes de los pueblos originarios, lo cual implica que las biografías de las personas certificadas pueden o no pueden corresponder a la tradición cultural aymara. Dada las dinámicas históricas regionales, es difícil establecer quiénes son y quiénes no son tales. Es posible que entre los inscritos se hallen personas que, teniendo un apellido considerado indígena, se ubique en aquella colectividad regional que ya no se siente vinculada al pueblo aymara, pero que la certificación le facilite el acceso a beneficios sociales (Beca Indígena, Subsidio habitacional, Programa Puente FOSIS, fondos concursables de la CONADI, entre otras). ${ }^{14}$ La base de datos de acreditaciones

\footnotetext{
${ }^{14}$ Conocemos varios casos de estudiantes, miembros de familias
}

confirma, además, una elevada demanda de solicitudes en el mes de Marzo, época en la que se convoca a postular a la Beca Indígena para estudios básicos, medios y superiores, la cual es gestionada por la Junta Nacional de Auxilio Escolar y Becas (JUNAEB).

Este beneficio es promovido en concordancia con las demandas históricas de los pueblos originarios por mayor acceso a la educación, ya que fue vista como una herramienta de movilidad social y una alternativa para reducir la condición histórica de desigualdad social. Este registro coincide con la demanda que se ha producido en los últimos años (2006-2010) por becas. Según las bases de datos de la JUNAEB, en 2010 alcanzó a 2205 becas entregadas de estudio (véase Figura 5).

Esta demanda por educación se refleja tanto en el aumento de las postulaciones como del número de becas adjudicadas. La Figura 6 muestra la curva ascendente de ambos indicadores, pero también expone la ampliación de la brecha entre los postulantes y los beneficiados en los cuatro años seleccionados. En los dos últimos años menos de la mitad de los postulantes logra esta ayuda estatal. En el sistema educacional se manifiestan con nitidez las profundas desigualdades generadas por la economía de libre mercado; en consecuencia, la entrega de subsidios estatales opera como mecanismo paliativo para disminuir las diferencias. Al mismo tiempo, el sistema escolar ha sido el principal instrumento del Estado para la integración nacional y la homogenización cultural. Para las familias aymara la educación de sus hijos e hijas constituye una de las principales vías de movilidad social (Podestá 1993; González 1996; González et al. 2000; Chipana 2000; Gundermann 2003).

Los subsidios no se agotan en la educación. Existen otros beneficios sociales que gozan de gran valoración entre la población rural como urbana. Entre ellos, el más importante es el subsidio habitacional. Desde el año 2007, las personas pertenecientes a los pueblos originarios pueden postular a un subsidio habitacional por su condición étnica y socioeconómica medida por un instrumento denominado Ficha de Protección Social.

nortinas con apellido de origen indígena pero distanciadas cultural y socialmente de la colectividad aymara, que han solicitado la certificación como un medio para acceder a becas. 


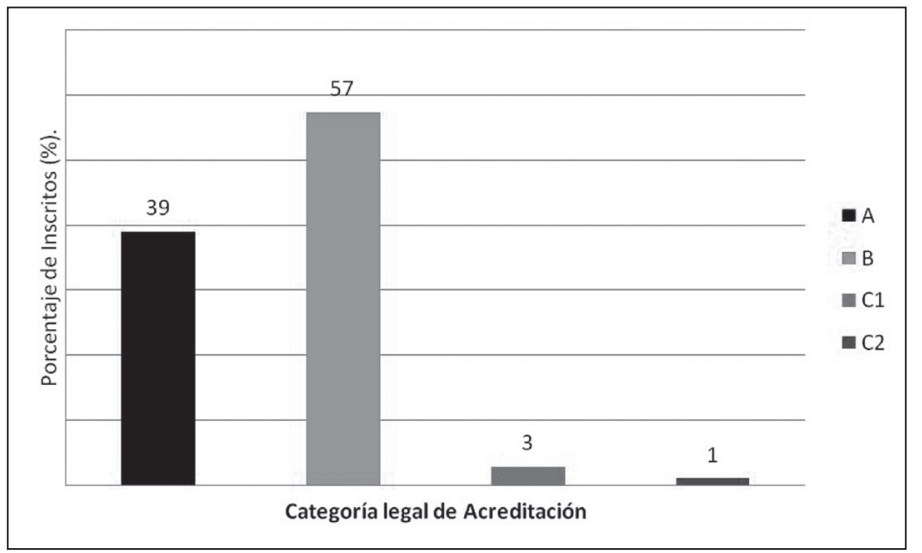

Figura 3. Cantidad de inscritos según tipo o categoría legal de acreditación (valores en porcentajes). Fuente: Elaboración Propia Base de datos CONADI Arica-Parinacota.

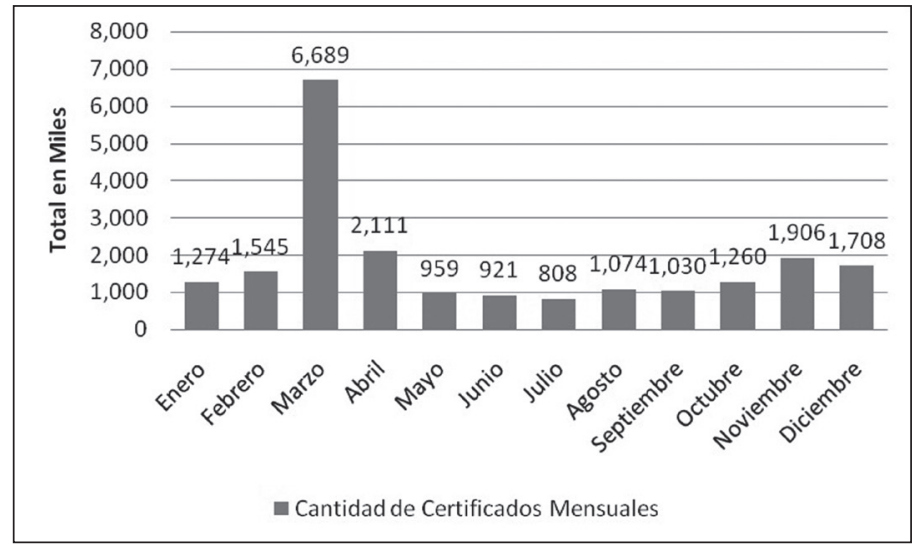

Figura 4. Cantidad mensual de solicitudes de acreditación de calidad de indígena, entre los años 1995-2008. Fuente: Elaboración Propia Registros Base de datos CONADI Arica-Parinacota.

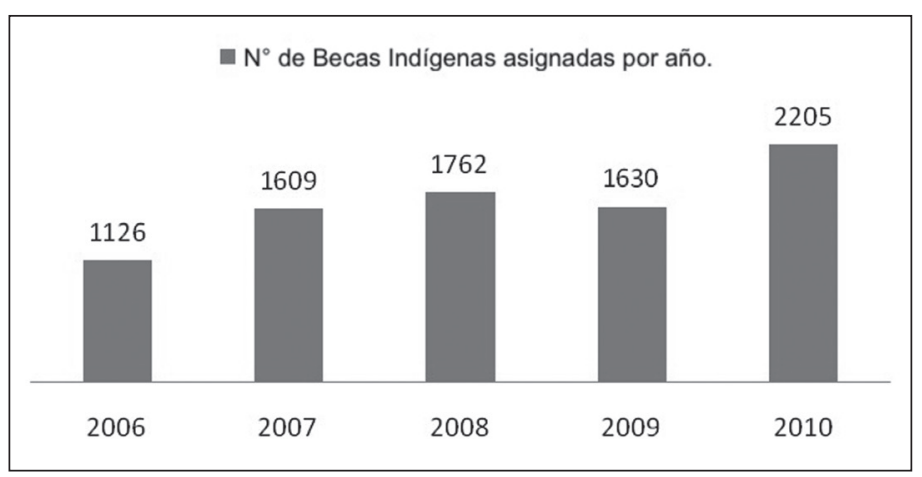

Figura 5. Gráfico con becas indígenas asignadas, JUNAEB, comuna de Arica 2006 al 2010. Fuente: registros JUNAEB vía Ley de Transparencia 20.285. 


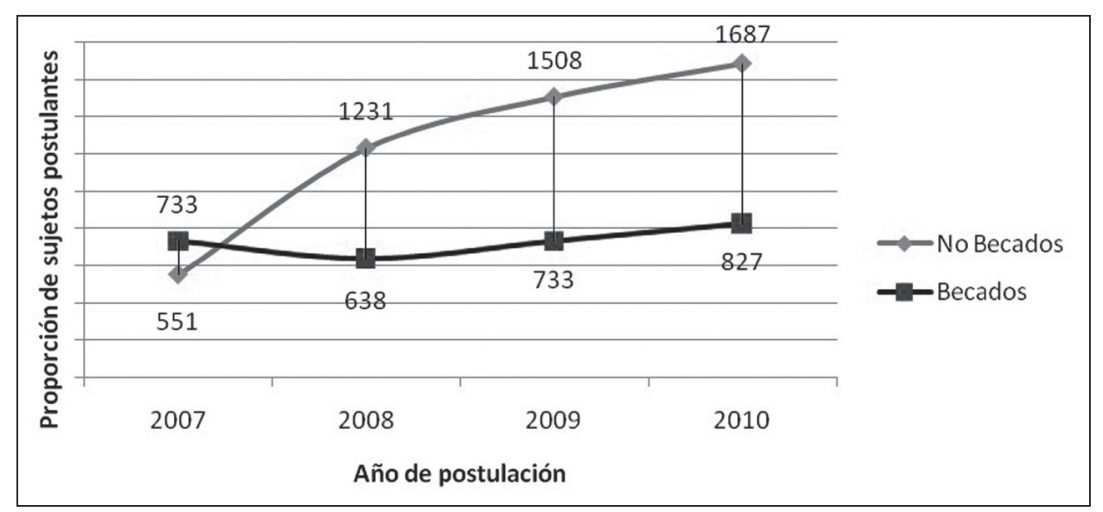

Figura 6. Cantidad anual de solicitudes de postulaciones a la Beca Indígena versus las postulaciones adjudicadas con Beca Indígena JUNAEB en la comuna de Arica entre los años 2007 y 2010. Fuente: Registros JUNAEB vía Ley de Transparencia $\mathrm{N}^{\circ} 20.285$.

\section{* La experiencia y valoración de LA CERTIFICACIÓN}

Las entrevistas se orientaron a averiguar el punto de vista de los actores acerca de la certificación, como una vía para conocer la visión de su condición de indígenas y ciudadanos. Se entrevistaron once personas. Mujeres y hombres de diferentes edades, con diferentes años de estudio y distintos años de residencia en la ciudad de Arica. Como se ha señalado más arriba, la certificación se produce tanto por iniciativa propia como por promoción de CONADI. Las redes parentales y los vínculos sociales son la plataforma para la comunicación acerca de los programas y sus beneficios. Una persona entrevistada nos relató lo siguiente:

“... La CONADI fue a los valles y me dijeron que si era indígena tenía que sacar un certificado, y después de eso fui a la oficina, me citaron para el otro día y me dieron una ficha para llenar y después retiré mi certificado, y de ahí hasta ahora hemos tenido más acercamiento con las autoridades mismas de la CONADI..." (Entrevista a I.D.Ñ.).

Los argumentos entregados permiten sostener que la certificación es una estrategia para acceder a beneficios sociales para formar parte de la comunidad nacional y política desde su condición de ciudadanos diferenciados. Ocho de los once entrevistados justifican la gestión del certificado por la postulación a la beca indígena para estudios secundarios o terciarios. Tanto para las familias aymara como para el Estado, la educación -que implica movilidad social y progreso- ha sido el principal camino para lograr una identidad moderna. Expresiones tales como "ver a sus hijos en buena posición", "progresar" se entienden en el camino hacia la superación del estigma de indio e integrarse a la sociedad mayor. A pesar de que el contexto escolar es un espacio difícil, hay que tratar de superar los obstáculos y esto se logra, precisamente, con mayor educación. En palabras de un entrevistado: “...ahora me da lo mismo porque siento que ahora tengo educación para defenderme". La legítima aspiración de proveer a las nuevas generaciones de mejores formas de vida, vinculada al ser indígena está presente en las narrativas:

“...Para no privarle a mis hijos de la posibilidad de estudiar como un indígena, de poder obtener las becas, de aquellas cosas que en el tiempo que yo estudié no existían, ó existían, pero por el hecho de no estar inscrito no las pude obtener y eso me limitó los estudios no pude seguir estudiando..." (Entrevista a E.I.A.).

La educación de hijos e hijas persiste con fuerza. Es un hecho que en la escuela se aprende a ser moderno, condición que se precisa para ser parte de la sociedad en la cual se insertan (Rival 2000), pero es precisamente en el espacio escolar, sobre todo en los contextos urbanos, donde se producen las mayores discriminaciones. A pesar de los avances que se han dado en torno a la diferencia cultural y étnica en la sociedad regional y nacional, el estigma de indio que, además, implica cuestionar la membresía nacional aún está presente y constituye un problema para la integración e inclusión en los contextos escolares. En este sentido se observa cierta resistencia de 
los jóvenes a asumir la diferencia. En el diálogo que se expone a continuación se puede apreciar la significación que uno de ellos otorga a la práctica de la certificación realizada por sus padres:

\section{"A: Entonces, ieres aymara?}

$B$ : No sé, pero un papel que había decía que sí.

A: Ya, pero, ¿tú no sabes si eres?

B: No sé.

(...)

A: Y'tú sacaste el certificado?

B: No.

A: Yiquién te lo sacó?

B: Mi papá yo creo ahh...

A: Ya, chas postulado a aloo con el certificado?

B:Mmm parece que sí, a la beca parece.

(...)

A: ¿El certificado te importa?

B: Eso sí.

A: ¿Por qué te importa?

$B$ : Porque no sé, no me gusta que me digan aymara.

A: ¿Por qué no te gusta que te digan aymara?

B: Porque en el papel, en el certificado dice aymara. No me gustaría tener eso ahí.

A: ¿No te gusta ser aymara?

B: No.

(...)

A: ¿Te has sentido incómodo con ese certificado?

B: Sí.

A: ¿Tú querías que lo sacaran?

B: No.

A: Y'iporqué no?

B: Porque hay algunos que por eso te molestan.

(...)

A: Yंqué te han dicho?

B: Que, no sé, peruano cholo.

A: Yंieso te molesta?

B: Sí.

A: ¿Qué harías tú con ese certificado?

B: No sé... lo anularía. Porque no me gusta que me molesten."

(Entrevista a J.B.B.).

Esto último implica un proceso de concienciación de su condición étnica en la sociedad nacional contemporánea que conduce a la negación. Pero el proceso de certificación en el contexto sociopolítico actual lleva también a otro lugar. El reconocerse como descendientes de los pueblos originarios considera reflexiones de la diferencia cultural y valoraciones de las tradiciones:

“...De mi parte más viene por sentido de reconocerme ante el Estado, de reconocerme como una persona practicante y que cultiva la idiosincrasia de la etnia aymara, ya sea sus mitos, sus costumbres y también por reconocerme ante los demás..." (Entrevista a O.V.).

Estos argumentos se repiten en varias entrevistas, lo que permite afirmar que la certificación legitima la diferencia cultural en la sociedad regional y nacional mayoritaria y los vincula de un modo diferente con el Estado. Ya sea que perciban un acercamiento antes inexistente, ya sea por hacer visible su estatus como miembro de una colectividad culturalmente diferenciada. Se ve como un requisito para ser reconocido por el Estado como miembro de una comunidad indígena "de un pueblo del interior", vale decir, de una comunidad histórica con derechos territoriales. Aunque en menor medida, la reivindicación política de derechos a la diferencia cultural está igualmente presente. Uno de los entrevistados señala que el Estado ha desvalorizado lo autóctono y ha supervalorado el proyecto civilizatorio occidental. En este sentido, argumenta que de cierta manera el Estado promueve una discriminación encubierta al alero de los beneficios sociales, invisibilizando las desigualdades y reproduciendo el estigma del indio. Dicho estigma se puede percibir en el énfasis que se le ha dado a la lengua castellana y a la desaparición de las lenguas vernáculas. Agrega que el pueblo aymara necesita una ciudadanía más activa que permita reclamar sus derechos, y para generar un cambio social y cultural en la sociedad nacional en favor de una sociedad igualitaria.

“...Lo que pasa es lo siguiente, el mismo Estado mató el origen y las costumbres (...) lo que sí tenemos que hacer como etnia es luchar para que se nos tome en cuenta, para cultivar nuestra etnia, ya no sólo a nivel de campo, porque en los pueblos falta mucho..." (Entrevista a A.M.S.).

Asimismo, los discursos muestran que otro efecto de esta estrategia estatal es un proceso reflexivo sobre las distintas formas de pertenencia a la colectividad aymara. Los actores distinguen claramente la membresía por las biografías personales, por los vínculos y el apego al territorio ancestral (comunidades rurales) y al uso de su 
propia lengua, de la pertenencia a una comunidad étnica en un contexto urbano y moderno, pero también, a una comunidad cívica que ha comenzado a situarlos en un estatus ciudadano diferente. Aspecto que no había ocurrido durante dos siglos, pues su integración significó negar sus culturas y luchar en contra del estigma de indio. Aunque este aún persiste, hoy se enfrenta con nuevas herramientas, principalmente mediante la valoración del pasado indígena. No obstante, la revaloración de las tradiciones supone un proceso de selección según la visión del no indio: fenotipo, religiosidad, música, gastronomía. Entre los aspectos destacados desde la alteridad construida por el grupo se hallan valores y comportamientos tales como el sacrificio, humildad, trabajo para progresar, capacidad de ahorro. Los entrevistados lo sintetizan en un conjunto de normas y una moral distintiva para la vida. Este valor se traduce como una cultura del esfuerzo y dedicación con el objetivo de mejorar las condiciones sociales y progresar para alcanzar mejor bienestar en el tiempo con humildad y reciprocidad.

“... A las personas indígenas las reconozco primero por su color de piel, su forma de caminar, hablar, su cuerpo es más notorio.

A: ¿En qué sentido?

B: En el sentido de que la gente del interior camina mucho; entonces va dando ciertos rasgos, en la forma de hablar, caminar, no se podría explicar con palabras, pero es como un caminar más humilde que el de las personas de la ciudad, las personas de la ciudad tienen como más desplante..." (Entrevista a E.I.A.).

"...Y uno alcanzó a comer todas esas cosas, como el maíz tostado con charqui, el sango, el piri que no se ve en la ciudad...”

A: ¿Cómo es el piri?

$B:$ El piri es hecho de harina, agua con sal que lo revuelven como miga, y se comía con queso y con charqui. Esta comida es bien rica que aquí en la ciudad no se ve y eso lo tienen guardado..." (Entrevista a E.S.I.).

“... Ser indígena aymara es una persona que practica sus costumbres ante los antepasados, de los tatarabuelos y eso para mí sería ser indigena, no es solamente tener un apellido, porque quizás vemos o hay muchas personas que tienen apellidos y que en cierto sentido sienten vergüenza (...) entonces para mí ser indígena es una persona que practica las creencias y practica la cultura y la difunde a los demás, eso para mí es ser indígena, más allá de tener un apellido y no tenerlo..." (Entrevista a O.V.).
"...Porque somos gente de mucho sacrificio, yo me considero una persona de grandes sacrificios, muy esforzada, yo nunca me voy a quedar atrás, así tenga que andar con un bastón, pero siempre le voy a echar para adelante y nunca le voy a tener miedo al trabajo, nunca..."(Entrevista a I.D.Ñ.).

Junto con la marcación de la frontera étnica, se erige otra hacia adentro de la colectividad. Los entrevistados distinguen los aymara y los descendientes aymara; los primeros son los que hablan la lengua y viven en las comunidades rurales, los segundos son las personas que residen en la ciudad y ya no hablan aymara. Una mujer se refiere a "ser de allá" (zona del interior) y "ser de acá" (la ciudad). Ella se vino de "allá" porque no quería continuar con el estigma de un sujeto indígena, ignorante. Migró para tener mejor acceso a educación y así poder educar a sus hijos.

"...Yo no soy aymara sino que descendiente aymara, ese es como yo me siento, así como un descendiente de la cultura aymara (...) no sé, una cuestión de más de una cosa que te dijeron, de que te enseñaron, onda mis padres a mí desde chico me dijeron que 'tú no eres aymara sino que descendiente aymara', como que mis padres me dijeron a mí desde chico que no éramos aymaras..." (Entrevista a M.F.V.).

\section{* Reflexiones finales}

De acuerdo con los antecedentes presentados, el aumento de las acreditaciones estatales de la pertenencia al pueblo aymara incluye una gran proporción de personas que nacieron en la ciudad de Arica, se trata de población joven y se produce principalmente durante el mes de marzo, al inicio del año escolar en Chile. Si a esto agregamos la creciente demanda por la obtención de becas estudiantiles frente a la Junta Nacional de Auxilio Escolar y Becas, podemos ver que la certificación es una estrategia para acceder a los beneficios sociales que otorga el Estado para la permanencia escolar. Este interés es comprensible porque la mayoría de la población aymara requiere de apoyo para la continuidad de sus estudios en un esquema en el que el mercado regula tanto el acceso como la calidad de la educación.

Los antecedentes cualitativos obtenidos confirman el fuerte interés de las personas por alcanzar mayores nive- 
les de escolaridad y éste tiende a ser el principal argumento para someterse al proceso de identificación estatal. Esto no es nada nuevo. La mayoría de los estudios sobre la comunidad aymara regional han señalado que, a lo largo del siglo XX, ésta ha optado por acceder al sistema educacional. Los datos confirman que a inicios del siglo XXI esta motivación sigue intacta. Este es el espacio en el que se logra un mejor manejo de la lengua castellana, se adoptan los emblemas de la comunidad imaginada y se instala la idea de la comunidad de iguales. Si bien los intentos del Estado por reconocer las diferencias culturales a través de la Educación Intercultural Bilingüe son una prueba concreta de respeto por la diversidad lingüística y cultural, la escolarización formal sigue siendo el espacio principal de producción y reproducción cultural del modelo occidental en las sociedades contemporáneas. Como señala Rival (2000) es la escuela la que ha creado y sigue creando las condiciones para que las identidades dominantes menoscaben la continuidad de las identidades minoritarias. Es cierto, por otra parte, que la colectividad aymara demanda cambios en el sistema escolar y apuestan por la educación intercultural y bilingüe. Postulan que las identidades culturales dependen del continuo uso escrito de las lenguas nativas y de su uso en la escuela, y que la educación estatal puede jugar un papel principal en el mantenimiento de las identidades culturales indias. Piensan que de este modo es posible restar influencia a la cultura dominante, pero esto se logra sólo hasta cierto punto. El sistema educativo chileno sigue siendo hegemónico al transmitir formas de organización en espacios temporales modernos e inhabilitan a las nuevas generaciones en relación con su conocimiento tradicional, alteran el medio ambiente natural y modifican las relaciones sociales tradicionales.

Siguiendo a Gundermann (2003) la certificación de la condición indígena de los ciudadanos y ciudadanas puede ser pensada como un nuevo mecanismo para continuar con el pacto establecido entre la comunidad aymara y el Estado. Se trata de acuerdos para avanzar hacia el progreso y la modernidad, pero este proceso va acompañado de un tipo de reconocimiento inédito en un contexto en el que el movimiento indígena ha adquirido notoriedad. A lo largo de los veinte años de vigencia de la nueva Ley Indígena es indudable que el escenario hegemónico ha cambiado. La política indigenista se expresa en un contexto neoliberal que reconoce al multiculturalismo como la estrategia para la convivencia nacional. El Estado declara un "nuevo" pacto social por la multiculturalidad llamado "Re-conocer", mismo que incluye el diseño de políticas de discriminación positiva. La certificación en este escenario cumple el rol de un nuevo instrumento de integración social, pero al mismo tiempo promueve espacios para un tipo de reconocimiento diferente de la etnicidad. Se podría hablar de una manera de estar en la comunidad nacional y política desde la etnicidad. Es decir, se es "indio" y ciudadano cuando los aymara son una colectividad cuyos miembros son conscientes de que su condición étnica le asigna un nuevo estatus en la comunidad política. Esto es, precisamente, lo que emerge desde la visión de los entrevistados.

Uno de los efectos del mecanismo de la certificación en los sujetos concretos es la expansión de un proceso de concienciación de su condición étnica en la sociedad nacional contemporánea. Se trataría de un requisito para ser reconocido por el Estado como miembro de una comunidad indígena, pero al mismo tiempo implica el reconocimiento de derechos a la diferencia cultural. En este contexto, la valoración de las tradiciones de los antepasados, la crítica a la homogenización cultural y a la imposición de un proyecto civilizatorio occidental va emergiendo desde abajo. Lo anterior va acompañado de un proceso reflexivo sobre las distintas formas de pertenencia a la colectividad aymara. Siendo la ciudad el principal espacio de residencia de la población en general y de quienes han solicitado la certificación, los actores distinguen la membresía a la comunidad indígena, de la membresía a una comunidad étnica en un contexto urbano y moderno: esto es, la pertenencia a la comunidad cívica que ha comenzado a situarlos en un estatus ciudadano diferente. En esta línea de razonamiento es posible afirmar, a modo de hipótesis, que el Estado chileno ha cumplido con sus objetivos de integración, pero si esta se ha logrado desde su condición étnica, desde los derechos a reivindicar una tradición cultural diferente, estaríamos en presencia de caminos hacia la inclusión social y cultural, vale decir, desde las exigencias de un pueblo que incorpora elementos de su tradición al proyecto civilizatorio nacional. Sin embargo, en un contexto de ciudadanía liberal y en lo económico en un modelo de libre mercado, no es fácil que la diferencia cultural esté presente en las políticas nacionales y regionales. Estos antecedentes ratifican la necesidad de continuar investigando acerca de la especificidad que 
adquiere hoy la relación pueblo aymara y Estado-nación chileno. La aceptación del nuevo pacto social por parte de los aymara y/o la administración de la etnicidad por parte de los gobiernos de los últimos catorce años en Chile ha generado dinámicas sociales y o políticas que requieren de mayores y mejores investigaciones para comprender la heterogeneidad cultural, social y política interna que ostenta la colectividad aymara.
Agradecimientos Este artículo forma parte del proyecto de Investigación Mayor en Ciencia y Tecnología de la Universidad de Tarapacá N³740-11, titulado "Relaciones sociales de mujeres y hombres de origen indígena. Diferencias culturales y desigualdades sociales del Norte Grande de Chile". Se agradece el apoyo del Convenio de Desempeño Universidad de Tarapacá y Ministerio de Educación Pública.

\section{$*$ Referencias citadas}

AYLWIN, J. 2004. Derechos humanos y pueblos indígenas. Tendencias internacionales y contexto chileno. Editorial Universidad de la Frontera, Temuco.

BELLO, A. 2004. Etnicidad y ciudadanía en América latina: la acción colectiva de los pueblos indígenas. Editorial Publicaciones Naciones Unidas, Santiago de Chile.

BENGOA, J. 2000. La emergencia indígena en América latina. Editorial Fondo de Cultura Económica, Santiago de Chile.

BENGOA, J. 2009. ¿Una segunda etapa de la emergencia indígena en América latina? Cuadernos de Antropología Social 29: 7-22.

BOCCARA, G. y P. BOLADOS. 2010. ¿Qué es el multiculturalismo? La nueva cuestión étnica en Chile neoliberal. Revista de Indias 70: 651-690. CSIC, Madrid.

CHIPANA, C. 200o. Percepción andina de la educación desde un punto de vista aymara. En Educación y Pueblo Aymara, (Eds.) S. González, F. Mena, C. Chipana, C. González, H. Alegría y P. García, pp. 68-96. Universidad Arturo Prat, Instituto de Estudios Andinos Isluga, Iquique.

GIMÉNEZ, G. 2000 . Identidades étnicas: estado de la cuestión. En Los Retos de la Etnicidad en los Estados Nación del Siglo XXI, R. Leticia (Ed.), pp. 45-70. CIESAS/ INI, México.

GONZALEZ, H. 1996. Los migrantes aymaras en la ciudad: acceso a educación, vivienda y salud. Serie Documentos de Trabajo, Corporación Norte Grande, Arica.

GONZÁleZ, S., S. GONZÁlEZ, F. MENA, C. CHIPANA, C. GONZÁLEZ, H. ALEGRÍA y P. GONZALEZ, H. y V. GAVILÁN. 1990. Cultura e identidad étnica entre los aymara del norte de Chile. Chungara 24/25: 145-158. Universidad de Tarapacá, Arica.

GUNDERMAN, H. 2003. Ciudadanía y poblaciones indígenas andinas de Chile. En El debate en torno al reconocimiento y los derechos ciudadanos. Mapuches y aymaras, H. Gundermann, R. Foerster y J. Vergara (Eds.) pp. 19-104. Universidad de Chile, PREDES, Santiago de Chile.

HOPENHAYN, M. 2001. ¿Integrarse o subordinarse? Nuevos cruces entre política y cultura. En: Cultura, politica y sociedad: Perspectivas Latinoamericanas, (Ed.) D. Mato, pp. 17-40. CLACSO, Consejo Latinoamericano de Ciencias Sociales, Ciudad Autónoma de Buenos Aires, Argentina.

HOPENHAYN, M., A. BELLO y F. MIRANDA. 2006. Los pueblos indígenas y afro descendientes ante el nuevo milenio, Naciones Unidas, Santiago de Chile.

RIVAL, L. 2000. La escolarización formal y la producción de ciudadanos modernos en la Amazonía ecuatoriana. En Etnicidades, A. Guerrero (Comp.), pp. 315-336. FLACSO/ILDIS, Quito.

PODESTA, J. 1993. Tradición oral aymara y educación: buscando nuevos caminos. Revista de Ciencias Sociales 2: 12-27.

VERGARA, J., H. GUNDERMANN y R. FOERSTER. 2006. Legalidad y legitimidad: Ley Indígena, Estado chileno y pueblos originarios (1989-2004). Estudios Sociológicos XXIV/ 2: 331-361. El Colegio de México, México D.F.

ZAPATA-BARRERO, R. 2004. Inmigración, innovación política y cultura de acomodación en España. CIDOB ediciones, Barcelona.

\section{Otras fuentes}

INE (2002). Censo de Población y Vivienda, Instituto Nacional de Estadísticas (Chile).

LEY INDÍGENA 19.253. (2004). Biblioteca del Congreso Nacional de Chile. Gobierno de Chile. Nuevo Trato con los Pueblos Indígenas. 